\title{
Strontium and Caries: A Long and Complicated Relationship
}

\author{
F. Lippert A.T. Hara \\ Department of Preventive and Community Dentistry, Oral Health Research Institute, Indiana University School of \\ Dentistry, Indianapolis, Ind., USA
}

\section{Key Words}

Caries prevention $\cdot$ Review $\cdot$ Strontium

\begin{abstract}
Investigations into the role of strontium (Sr) in caries prevention have attracted great interest in the research community in the past, with their peak in the 1970-80s. To this date, no clear indication of the relative importance of $\mathrm{Sr}$ in caries prevention has been provided. A vast number of animal caries, epidemiological and mechanistic studies have been conducted. Although there is much discrepancy, the majority of studies suggest that $\mathrm{Sr}$ exhibits some cariostatic properties, predominantly in the presence of fluoride. An optimum $\mathrm{Sr}$ concentration of 5-10 ppm in drinking water has been proposed as a direct result of several epidemiological caries studies. Despite these results, no direct link can be established between $\mathrm{Sr}$ and caries prevention as, to date, no relevant, randomized controlled trials have been reported. The extrapolation of potential cariostatic properties of $\mathrm{Sr}$ from epidemiological studies is difficult due to the co-presence of several other trace elements in the water of the study areas, with many of these elements being attributed cariostatic properties in their own right. Furthermore, the role of caries risk factors was not taken into consideration. There is a clear need for further research, especially on the mineral phases in the dental hard tissues, plaque and plaque fluid associated
\end{abstract}

with $\mathrm{Sr}$ as these may give rise to a better understanding of this subject matter. Based on the current data, the cariostatic properties of $\mathrm{Sr}$, or at least those proposed by some authors, cannot be supported. Copyright $\odot 2012$ S. Karger AG, Basel

The caries-preventative effects of fluoride (F), and especially its sodium salt, have long been established and are beyond any reasonable doubt. However, despite F's proven track record, caries is still endemic in populations globally and its elimination will remain the main challenge for dental researchers for decades to come. Its main negative side effect, fluorosis, has led investigators to conduct research on other, preferably non-toxic, (trace) elements, ideally exhibiting synergy with $\mathrm{F}$, and their relative anti-caries effects - one being strontium (Sr).

Due to its similarity to calcium (Ca), Sr has attracted a considerable amount of interest in the caries and cariesrelated research community, with its peak in the 1970s and 1980s. Despite a vast number of animal caries, epidemiological and mechanistic studies conducted by various investigators, to this date, no clear indication of the role of $\mathrm{Sr}$ in caries prevention has been provided. Previous reviews on the relationship between trace elements in general and caries [e.g. Büttner, 1969; Losee and Ludwig, 1970; Navia, 1972; Anonymous, 1978; Curzon and Crock-

\section{KARGER}

Fax +41613061234

E-Mail karger@karger.ch

www.karger.com
(C) 2012 S. Karger AG, Basel

$0008-6568 / 13 / 0471-0034 \$ 38.00 / 0$

Accessible online at:

www.karger.com/cre
Frank Lippert

Department of Preventive and Community Dentistry, Oral Health Research Institute Indiana University School of Dentistry

415 Lansing Street, Indianapolis, IN 46202 (USA)

E-Mail flippert@iupui.edu 
er, 1978; Beaton, 1983; Olson, 1987] highlighted the complexity of the matter, but were also somewhat limited in scope. Therefore, the aim of the present paper was to critically and comprehensively review the literature concerned with the role of $\mathrm{Sr}$ in the caries process.

\section{Search Strategy and Structure}

A search strategy was developed for articles indexed in MEDLINE, Web of Science ${ }^{\circledR}$ and PubMed databases written in English up to August 30, 2011. Several hand searches were required to obtain articles which could not be retrieved via the aforementioned databases. The following key words were used in the searches in combination with 'strontium' or 'sr': 'caries', 'tooth', 'teeth', 'enamel', 'dentin*', 'demin*', 'remin*', 'apatite', 'hydroxyapatite', 'calcium phosphate', 'fluoride'. Articles were then divided into the following groups based on the topics investigated, which will also form the order of the present review: (1) Sr studies in animals - Sr effects on dentin and enamel, animal caries studies; (2) epidemiological caries studies; (3) Sr in oral care products; (4) Sr in the oral cavity presence in teeth, plaque and saliva; (5) $\mathrm{Sr}$ and calcium phosphates (CaPi); (6) discussion; (7) conclusions. Articles concerned with multiple topics were considered in all relevant groups.

\section{Sr Studies in Animals}

\section{Sr Effects on Dentin and Enamel}

There is a discrimination against $\mathrm{Sr}$ in $\mathrm{CaPi}$ mineralization when $\mathrm{Ca}$ is present (see also ' $\mathrm{Sr}$ and $\mathrm{CaPi}$ '), which was shown by Likins et al. [1959] in weanling rats. Later studies [Likins et al., 1961; Menczel et al., 1962] were able to support these findings, and a higher Sr discrimination was found in dentin in relation to enamel [Likins et al., 1961].

Studies in weanling rats [Likins et al., 1959] have shown that when both $\mathrm{Ca}$ and $\mathrm{Sr}$ were present during tooth formation, $\mathrm{Ca}$ was incorporated into the apatitic lattice preferentially, resulting in a higher $\mathrm{Ca}$ :Sr ratio in the subsequent mineral than might be expected. Later studies [Likins et al., 1961; Menczel et al., 1962] were able to support these findings, with the effect more pronounced in dentin than in enamel [Likins et al., 1961].

Sr injections were shown to cause dentin hypomineralization in rats, resulting in the formation of a hypomineralized layer of dentin, comparable to that seen after
F injection [Weinmann, 1942; Irving and Weinmann, 1948; Yaeger, 1963]. These effects were almost entirely confined to dentin as enamel was not affected [Weinmann, 1942]. Yaeger and Eisenmann [1963] showed that the degree of dentin hypomineralization was positively correlated to [Sr] (i.e. Sr concentrations). Although a similar correlation was found for [F], the wider zones of hypomineralized dentin observed for $\mathrm{Sr}$ and the lack of a thinner hypermineralized layer of dentin as observed for F suggested differences in their etiology. A later study [Yaeger et al., 1964] suggested that Sr (or F) inhibit or reverse the matrix aggregation normally occurring at the dentin-predentin junction, thus inhibiting mineralization. Grady and Yaeger [1965] reported that, while in normal dentin collagen fibrils are orientated perpendicular to the dentinal tubules, in hypomineralized layers caused by $\mathrm{Sr}$ (or F), fibrils are arranged at $45^{\circ}$ to the fibrils of the normal dentin. The possibility that hypomineralized dentin can recover after Sr injection ceases was shown by Yaeger [1966]. Regions of hypomineralized rat dentine induced by $\mathrm{Sr}$ (or F) were reported to show greater ability to mineralize than adjacent untreated dentine in vitro [Eisenmann and Yaeger, 1972]. Johnson et al. [1970] demonstrated that $\mathrm{Sr}$ was not lost preferentially from high-Sr dentin and suggested that $\mathrm{Sr}$ was not predominantly located at the surface. In addition, many studies reported that $\mathrm{Sr}$ injection causes the formation of more than one hypomineralized layer in dentin [Yaeger and Eisenmann, 1963; Yaeger et al., 1964; Eisenmann and Yaeger, 1969; Ogawa et al., 1981]; however, while two hypomineralized layers were reported in labial dentin, only a single layer was found in lateral, medial and lingual walls [Ogawa et al., 1981; Appleton, 1993]. Ogawa et al. [1981] postulated that $\mathrm{Sr}$ may exert its effect on dentin hypomineralization not only because of its ability to retard crystal growth, but also because of a direct effect on odontoblasts and collagen synthesis.

Castillo Mercado and Bibby [1973] studied the effects of Sr injections on molar morphology and found wider fissures and thicker dentin. A subsequent study [Curzon et al., 1982] investigating $\mathrm{Sr}$ effects when given in drinking water found an increase in horizontal and vertical dentin thickness at a [Sr] of $50 \mathrm{ppm}$, but not at $150 \mathrm{ppm}$ which was indistinguishable in its effect to the water control.

While Sr effects on dentin were studied almost solely as a result of $\mathrm{Sr}$ injections, i.e. systemically, its effects on enamel were predominantly studied as a result of dietary Sr administration. Johnson et al. [1966] and Johnson [1967] demonstrated that isomorphous substitution of Sr 
for $\mathrm{Ca}$ occurs in the enamel-HAp and postulated that $\mathrm{Sr}$ may form $\mathrm{Sr}_{6} \mathrm{H}_{3}\left(\mathrm{PO}_{4}\right) \cdot 2 \mathrm{H}_{2} \mathrm{O}$, which was shown to be a precursor of Sr-HAp [Collin, 1966]. Furthermore, Johnson and Singer [1967] found a gradient of increasing [Sr] from the incisal to apical areas in enamel of rats raised on a Sr-rich diet.

Similar to its effects on dentin, Sr has been shown to cause disturbances in ameloblast morphology and amelogenesis [Weinmann, 1943; Neiman and Eisenmann, 1975] in rats when injected. White et al. [1980] demonstrated that the enamel organ limits Sr uptake in both the secretory and maturation phases of enamel formation. A further study by Suga et al. [1987] supported these findings and reported that $\mathrm{Sr}$, unlike $\mathrm{F}$, inhibits the early stage of enamel maturation and that mineralization ceases earlier in the inner layers of Sr-treated rats than in control groups.

Sr uptake by surface enamel of rats given water with different [Sr] (0-100 ppm) was studied by Spector et al. [1978]. The authors found a dose-response relationship between $[\mathrm{Sr}]$ administered and $[\mathrm{Sr}]$ in surface enamel, but only when Sr was given pre- and post-eruptively. When given pre-eruptively only, a [Sr] of $50 \mathrm{ppm}$ yielded the highest Sr uptake. Comparing the relative pre- and posteruptive contributions to [Sr] in surface enamel, the present authors calculated that at $[\mathrm{Sr}] \leq 50 \mathrm{ppm}, 70-74 \%$ of [Sr] in surface enamel of rats was due to $\mathrm{Sr}$ given preeruptively, while at $[\mathrm{Sr}]=100 \mathrm{ppm}$, only $29 \%$ could be attributed to Sr given pre-eruptively. A subsequent study [Curzon and Spector, 1980] showed some variations between different $\mathrm{Sr}$ salts in Sr uptake by enamel, especially when administered pre-eruptively. A dose-response relationship between $[\mathrm{Sr}]$ administered through the diet and [Sr] in surface and near-surface enamel was also observed by Ashrafi et al. [1980].

\section{Animal Caries Studies}

Before relevant $\mathrm{Sr}$ animal caries is discussed, some light must be shed on differences in the etiology of caries in animals and humans. Ericsson [1962] and Tatevossian and Wright [1974] have shown that rat in comparison to human saliva exhibits higher $\mathrm{pH}$ values, lower $[\mathrm{P}]$ but higher [Ca] and a considerably higher buffering capacity, presumably due to higher $\left[\mathrm{CO}_{3}\right]$. In addition, Haldi et al. [1960] have demonstrated that the $\mathrm{pH}$ at the tooth surface of rats 'rarely fell as low as 7.0' after the administration of a cariogenic diet or sugar alone. In a review, White [1992] concluded that while animal models have tremendous value in studying the caries process, they are by no means perfect profile tools, and that results of animal caries studies on new anti-caries agents and formulations do not necessarily mirror clinical results (differences in anticaries effectiveness and efficacy observed in animal caries studies and randomized controlled trials between amine fluoride, MFP and NaF are worth noting in this context). Furthermore, the duration and frequency of administration, salivary clearance of actives and the effect of diet on retention of actives are not well understood in animals, making comparisons to caries in humans difficult and highlighting that further research is warranted in this area.

Animal studies on the effects of Sr in preventing caries have been equivocal as no effects [Johansen and Hein, 1953; Olson et al., 1978], an increase [Hunt and Navia, 1975; Joseph et al., 1977] or a decrease [Losee and Adkins, 1968; Gedalia et al., 1975; Meyerowitz et al., 1979; Ashrafi et al., 1980; Curzon and Spector, 1981; Curzon, 1988] in caries incidence have been reported. Generalization of Sr effects, however, is unjustified as differences depending on the dose and time of administration (pre- and/or post-eruptively) or the combined administration of Sr and F need to be analyzed for separately. In addition, scoring of animal caries was not uniform between these studies, thus further complicating the matter. Accordingly, the present authors decided to conduct further analyses only on studies using the caries scoring method according to Keyes [1958]. Individual 'E' scores (enamel units) for bucco-lingual, sulcal and proximal lesions were combined to yield a total caries score in line with the 'Indiana rat caries model', and subsequently, percentage values of caries reduction were calculated in relation to appropriate controls [Stookey et al., 1995]. The results of the rat caries studies conducted by Meyerowitz et al. [1979], Ashrafi et al. [1980] and Curzon [1988] are presented in table 1 . Studies are comparable to some extent due the same diet (MIT 200) being fed, although rats were inoculated with Streptococcus mutans only in the study by Curzon [1988]. Comparing these data it can be noted that there is a curvilinear relationship between [Sr] administered and caries reduction, regardless of whether $\mathrm{Sr}$ was administered pre- and/or post-eruptively. However, caution must be issued as no statistical analysis is possible due to the unavailability of the raw data. The reason for this curvilinear behavior is not clear and cannot be sufficiently explained based on what is currently known. However, Driessens $[1982,1986]$ proposed some hypotheses which will be discussed at a later stage. In this context, it is worth mentioning that data can be overor even misinterpreted if caries scores from only one particular site, or the wrong comparisons, are considered. 
Table 1. Rat caries reduction as a function of Sr dose pre- and posteruptively in the presence or absence of $\mathrm{F}$

\begin{tabular}{|c|c|c|c|c|c|c|}
\hline Pre/post ${ }^{\mathrm{a}}$ & $\mathrm{n}$ & $\mathrm{Sr}^{\mathrm{b}}$ & $\mathrm{F}^{\mathrm{b}}$ & $\begin{array}{l}\mathrm{E} \\
{\text { (total })^{\mathrm{c}}}\end{array}$ & $\begin{array}{l}\% \text { change } \\
\text { vs. water }\end{array}$ & $\begin{array}{l}\% \text { change } \\
\text { vs. fluoride }\end{array}$ \\
\hline \multicolumn{7}{|c|}{ Meyerowitz et al. [1979] } \\
\hline \multirow[t]{8}{*}{ Pre } & 10 & 0 & 0 & 29.6 & - & - \\
\hline & 10 & 2.5 & 0 & 23.2 & -21.6 & - \\
\hline & 9 & 5 & 0 & 21.5 & -27.4 & - \\
\hline & 10 & 10 & 0 & 25.4 & -14.2 & - \\
\hline & 10 & 0 & 1 & 28.5 & -3.7 & - \\
\hline & 9 & 2.5 & 1 & 26.5 & -10.5 & -7.0 \\
\hline & 10 & 5 & 1 & 24.4 & -17.6 & -14.4 \\
\hline & 10 & 10 & 1 & 26.7 & -9.8 & -6.3 \\
\hline \multirow[t]{7}{*}{ Post } & 10 & 0 & 0 & 21.4 & - & - \\
\hline & 9 & 50 & 0 & 18.2 & -15.0 & - \\
\hline & 10 & 100 & 0 & 23.4 & +9.3 & - \\
\hline & 10 & 150 & 0 & 21.3 & -0.5 & - \\
\hline & 10 & 0 & 10 & 13.2 & -38.3 & - \\
\hline & 8 & 50 & 10 & 14.2 & -33.6 & +7.6 \\
\hline & 10 & 100 & 10 & 15.4 & -28.0 & +16.7 \\
\hline
\end{tabular}

\begin{tabular}{lllllll}
\hline Ashrafi et al. [1980] & & & & \\
Pre + post & 5 & 0 & 0 & 35.4 & - & - \\
& 5 & $0.5+5$ & 0 & 29.3 & -17.2 & - \\
& 5 & $1.0+10$ & 0 & 24.8 & -29.9 & - \\
4 & $2.5+25$ & 0 & 28.3 & -20.2 & - \\
8 & $5.0+50$ & 0 & 29.9 & -15.6 & - \\
6 & $7.5+75$ & 0 & 21.5 & -39.3 & - \\
\hline
\end{tabular}

Curzon [1988]

$\begin{array}{rlcrrr}10 & 0 & 0 & 34.9 & - & - \\ 10 & 0 & 10+10 & 21.7 & -37.8 & - \\ 10 & 0.5+5 & 10+10 & 24.1 & -30.9 & 11.1 \\ 10 & 5+50 & 10+10 & 17.0 & -51.3 & -21.7 \\ 10 & 10+100 & 10+10 & 19.2 & -45.0 & -11.5 \\ 10 & 15+150 & 10+10 & 17.8 & -49.0 & -18.0 \\ 8 & 20+200 & 10+10 & 19.1 & -45.3 & -12.0 \\ 10 & 30+300 & 10+10 & 20.0 & -42.7 & -7.8\end{array}$

${ }^{a} \mathrm{Sr}$ and/or F given pre- or post-eruptively. ${ }^{\mathrm{b}}$ Concentration in $\mu \mathrm{g} / 10 \mathrm{~g}$ body weight if given pre-eruptively, or in $\mathrm{mg} / \mathrm{l}$ if given post-eruptively (water) ${ }^{\mathrm{C}}$ Sum of bucco-lingual, sulcal and proximal enamel caries scores. ${ }^{\mathrm{d}}$ Negative values are indicative of caries reduction, positive values indicate increase.

Meyerowitz et al. [1979] concluded that a combination of $50 \mathrm{ppm}$ Sr and $10 \mathrm{ppm}$ F resulted in the greatest reduction in bucco-lingual rat caries scores. The authors, however, ignored sulcal and proximal caries scores where $\mathrm{Sr}+\mathrm{F}$ was less effective in reducing caries than $\mathrm{F}$ alone. The present authors combined all three scores and found a $7.6 \%$ increase in rat caries in comparison to $\mathrm{F}$ alone (table 1), thus the opposite result (this may or may not be of statistical significance).

Critical Review on Strontium and Its Role in Caries
Other animal caries studies will now be considered. Johansen and Hein [1953] found no cariostatic effect for Sr when administered to hamsters at $50 \mathrm{ppm}\left(\mathrm{as}_{\mathrm{SrCl}}\right)$ in the drinking water. Shaw and Griffiths [1961] studied the effects of dietary $\mathrm{Sr}$ supplementation on rat caries (using the sparingly soluble $\mathrm{SrCO}_{3}$ ). A positive effect, i.e. a caries reduction, was noted when administered post-eruptively; however, this was paired with a decrease in weight gain by the animals (at $2 \% \mathrm{SrCO}_{3}$ ). When given pre-eruptively, an increase in caries occurrence was noted, and this could not be offset by giving $\mathrm{Sr}$ post-eruptively to the same rats. Losee and Adkins [1968] studied the effects of a dietary supplementation with the ash of green beans cooked in water containing different amounts of trace elements. The lowest overall caries scores could be related to the water sourced from Ohio, rich in Li, Mo, Sr, B and F. As multiple trace elements were present, no direct relationship for Sr in reducing caries could be established. A later study [Losee et al., 1976], investigating the effect of the 'Ohio water' when given to rats in comparison to deionized water, concluded that these trace minerals may act synergistically with $\mathrm{F}$ in reducing caries prevalence in rats.

When $\mathrm{Sr}\left(\mathrm{as} \mathrm{SrCl}_{2}\right)$ was administered pre-eruptively at concentrations of 1,000 or $2,000 \mu \mathrm{g}$ per $10 \mathrm{~g}$ body weight, an increase in rat caries was noted [Hunt and Navia, 1975]. However, at $100 \times$ or $200 \times$ the maximum [Sr] as compared to the study by Meyerowitz et al. [1979] the physiological relevance is questionable. A later study by the same authors [Hunt and Navia, 1975] found similar effects at $[\mathrm{Sr}]=500 \mu \mathrm{g}$ in the presence or absence of $[\mathrm{F}]=$ $100 \mu \mathrm{g}$ per $10 \mathrm{~g}$ body weight, thus indicating no additive or synergistic $\mathrm{Sr}+\mathrm{F}$ effects. However, both studies reported incomplete rat caries scores, which does not allow for decisive conclusions to be drawn. Gedalia et al. [1975] found a somewhat similar curvilinear relationship as noted above when studying the effects of $\mathrm{Sr}$ in water on caries in hamsters when given post-eruptively. $[\mathrm{Sr}]=$ $25 \mathrm{ppm}$ resulted in an overall increase, whereas $[\mathrm{Sr}]=$ $75 \mathrm{ppm}$ resulted in a decrease of caries occurrence. Considerably stronger Sr effects were noted when Sr was administered pre-eruptively, and both $[\mathrm{Sr}]$ resulted in a marked decrease in caries in a dose-response manner. These results mirror later observations by Meyerowitz et al. [1979] and it was concluded that Sr exhibits its cariostatic effect mainly because it is laid down in enamel and dentin before eruption, therefore excluding topical effects to some extent.

Joseph et al. [1977] found a marginal increase in caries in hamsters when $\mathrm{Sr}$ was given pre- and post-eruptively 
as part of the drinking water at 10 and $25 \mathrm{ppm}$. F was found to offset the negative Sr effects. Similar effects were reported on rats exposed to Sr post-eruptively by Olson et al. [1978]. Curzon and Spector [1981] studied the effects of different $\mathrm{Sr}$ salts at $[\mathrm{Sr}]=50 \mathrm{ppm}$ on rat caries reduction and concluded that $\mathrm{SrF}_{2}$ was most effective, mainly because of its $[\mathrm{F}]=22 \mathrm{ppm}$. Other salts varied in their effectiveness based on their bioavailability. In addition, $\mathrm{Sr}$ effects were somewhat greater when given post- than preeruptively.

Seppä et al. [1988] reported that a total of two treatments with 500 ppm Sr with or without NaF varnish application had no effect on rat caries in comparison to the appropriate controls. Luoma et al. [1984] studied the effects of chlorhexidine (CHX)-F-Sr ([Sr] = 1,000 ppm) and found a reduction in fissure caries and approximal lesions, but an increase in plaque scores in relation to CHX-F. In a subsequent study, Spets-Happonen et al. [1996] found a similar curvilinear Sr caries relationship as reported before, as a CHX-F gel supplemented with 50 ppm Sr did show some marginal benefits in reducing rat caries, whereas $250 \mathrm{ppm} \mathrm{Sr}$ appeared to markedly weaken the CHX-F effect.

\section{Epidemiological Caries Studies}

Several major questions are pertinent when analyzing data from epidemiological studies: (a) is the relationship between $\mathrm{Sr}$ and caries reduction causative or simply incidental?, and (b) is the reduction in caries related to the sole contribution of Sr, or is it due to the additive or synergistic action of two or more trace elements present at the same time? Furthermore, as both topical and systemic effects are thought to play roles in the caries-preventative action of Sr (see 'Animal Caries Studies'), it is necessary to consider whether subjects were lifelong residents of, or if they immigrated to the study area (i.e. the area from which water or soil samples were taken and analyzed for [Sr]). In case they immigrated, when (i.e. pre- or post-eruptively in relation to their permanent dentition), and what were environmental $[\mathrm{Sr}]$ in their previous area. Finally, what were the oral care habits of the study subjects, their age, socioeconomic status and sugar intake/ dietary habits, i.e. have caries risk factors been considered? To the authors' knowledge, not a single study was concerned with all these aspects, thus making it almost impossible to perform an unbiased review of the available studies, which, sadly, are therefore only of very limited value. Nonetheless, epidemiological studies will be dis- cussed in chronological order and in the context of the information provided.

Anderson [1966] studied a relatively small group of 12 -year-old children $(n=51)$ from an area in Gloucestershire (UK) whose soil is rich in $\mathrm{SrSO}_{4}$. [ $\left.\mathrm{Sr}\right]$ in water in this area was estimated at $0.33 \mathrm{ppm}$ and therefore extremely low in comparison to later studies (see below), whereas [F] was $0.15 \mathrm{ppm}$. No differences in DMF scores (6.03 vs. $5.63)$ between the study area and a control area $(\mathrm{n}=537$; $[\mathrm{Sr}]=$ nil; $[\mathrm{F}]=0.13-0.15 \mathrm{ppm})$ were observed, but considerably lower DMF scores (4.36 and 4.38) were noted in ' $\mathrm{F}$ areas' $(\mathrm{n}=74 ; \mathrm{F}]=0.9 \mathrm{ppm})$ and 'Mo areas' $(\mathrm{n}=270$; $[\mathrm{Mo}]=0.0036 \mathrm{ppm} ; \mathrm{F}]=0.09 \mathrm{ppm})$.

During a study on caries-resistant navy recruits [Losee and Adkins, 1969], which was perhaps the key study that sparked interest in Sr in the caries research community in the 1970s, it was possible to correlate the high number of caries-resistant recruits from NW Ohio (USA) with the simultaneous occurrence of elevated [B], [Li], $[\mathrm{Mo}],[\mathrm{Sr}]$ in NW Ohio water in combination with F. A median $[\mathrm{Sr}]$ of $6,100 \mathrm{ppm}$ was found in the water of the study area and the transfer of F, Li, Mo and Sr from water to green beans during cooking was shown. A subsequent rat caries study [see above; Losee et al., 1976] was able to support the findings of this epidemiological study. Losee and Bibby [1970] were able to negatively correlate [Sr], [B] and $[\mathrm{F}]$ in water with DMFT scores $(\mathrm{r}<-0.8$ for $\mathrm{Sr}, \mathrm{B}$ and F) based on the data from six cities in Illinois (USA). A more comprehensive study by Adkins and Losee [1970] compared trace elements in water between low and high caries status (in the USA) and found significant differences between the two for $\mathrm{Ba}, \mathrm{B}, \mathrm{Li}, \mathrm{Mo}$ and $\mathrm{Sr}$ with higher concentrations observed in states with lower caries incidence. Strong, positive co-variations were found between these trace elements, and Sr was found to exhibit the lowest correlation coefficient with caries prevalence $(\mathrm{r}=-0.59)$, thus indicating the strongest effect. $\mathrm{F}$, however, was not considered.

A study [Curzon et al., 1970] on 251 children aged 1214 years from two towns in Ohio (USA) with different [Sr] (5.37 vs. $0.2 \mathrm{ppm})$ and [B] (0.35 vs. $0.04 \mathrm{ppm})$ and similar [F] (1.2 vs. $1 \mathrm{ppm}$ ) showed mean DMFS scores of 3.56 versus 5.54 and mean DMFT scores of 2.25 versus 3.04, and it was concluded that differences in $[\mathrm{B}]$ and $[\mathrm{Sr}]$ in water were attributable to the reduction in caries rather than the $0.2 \mathrm{ppm}$ difference in [F]. It must be noted that only subjects with fully erupted canines, premolars and second molars were included in the study. A 10 -year followup study [Curzon, 1983] found essentially the same caries distribution pattern between these communities and the 


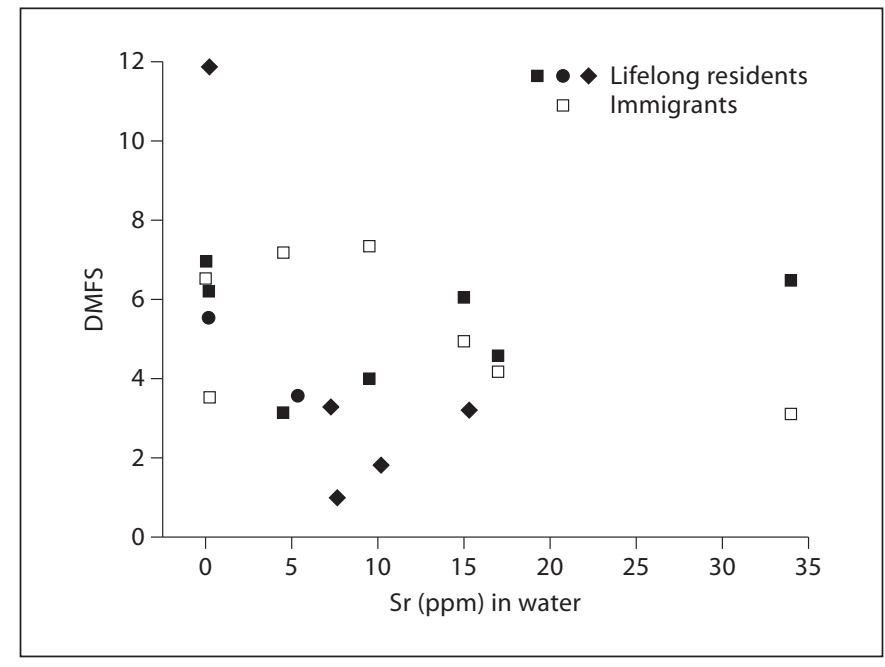

Fig. 1. Summary of three epidemiological studies on effects of $\mathrm{Sr}$ in water on caries occurrence (measured as DMFS scores): Data from Curzon et al. [1978] ( $\square, \square)$, Curzon et al. [1970] (O) and Curzon [1985] ( $)$.

changes in DMFS scores were attributed to changes in [Sr] in water. Ludwig et al. [1970] also studied children aged 12-14 years (who were lifelong residents) from 19 towns in various states (in the USA) with very low $[\mathrm{F}]$ in water $(0-0.30 \mathrm{ppm})$ but different DMFT scores (3.8-9). [Sr] in water ranged from 12 to $2,200 \mathrm{ppm}$, but only a weak negative correlation between $[\mathrm{Sr}]$ and DMFT was established $(r=-0.29)$. Again, Sr and B $(r=-0.3)$ showed similar effects. However, the present authors calculated that the exclusion of the two towns with the highest [Sr] of 1,300 and $2,200 \mathrm{ppm}$ (leaving [Sr] $=280 \mathrm{ppm}$ the next highest) would have yielded $r=0.03$ and therefore no correlation at all. An investigation into differences in caries activity between two semi-isolated communities in Colombia with $[\mathrm{F}]<0.2 \mathrm{ppm}$ in water by Bowen et al. [1977] did not find a relationship between [Sr] in water (8$120 \mathrm{ppm}$ in low and $14 \mathrm{ppm}$ in high caries activity communities) and caries activity. However, water $[\mathrm{B}]$ were substantially different (21-85 ppm vs. $1.5 \mathrm{ppm}$ ).

Perhaps the most compelling set of data was reported by Curzon et al. [1978] who conducted caries examinations on 1,313 children aged 12-14 years, lifelong residents and immigrants, living in seven communities in Wisconsin (USA). [F] in drinking water was comparable between communities with 1-1.29 ppm; however, [Sr] varied between 0.022 and $33.94 \mathrm{ppm}$. Figure 1 shows the results of this study in combination with the results of two comparable studies by Curzon et al. [1970] and Cur- zon [1985]. As water [F] were almost identical and as the caries evaluation was performed similarly, all three studies were combined. Considering lifelong residents only, an optimum [Sr] in water in relation to caries prevention is suggested. It is worth mentioning that as concentrations of other trace elements in water were also provided, the present authors found a very similar relationship for $[\mathrm{Fe}]$ and a linear relationship for [B]. In relation to the findings with regard to $\mathrm{Fe}$ and $\mathrm{B}$ it must be mentioned that a follow-up study by Curzon [1983] found essentially the same $[\mathrm{B}]$ but considerably lower $[\mathrm{Fe}]$ in water in the areas studied. Somewhat surprising were the results of the immigrants, showing an almost inverse relationship compared to lifelong residents. No information regarding their previous $\mathrm{Sr}$ exposure was presented and, regrettably, the authors did not discuss these data, making it difficult to provide any comments now. The final study by Curzon [1985] also reported an inverse correlation between caries prevalence and $[\mathrm{Sr}]$ in water in communities with water [F] of 0.9 to $1.2 \mathrm{ppm}$. It should also be mentioned that the method for determining carious surfaces was somewhat inappropriate as 'any fissure or enamel surface in which the explorer stuck and penetrated into dentine was regarded as carious' [Curzon et al., 1978].

In contradiction to earlier studies [Ludwig et al., 1970; Bowen et al., 1977], showing no or only marginal anticaries benefits for $\mathrm{Sr}$ in the presence of low $[\mathrm{F}]$, Athanassouli et al. [1983] were able to correlate lower DMFT scores (5.26 vs. 6.95) in 582 children aged $11-14$ years with an area of higher $[\mathrm{Sr}]$ in water $(2.9-7 \mathrm{ppm}$ vs. $0.2-$ $1.3 \mathrm{ppm})$. [F] in water was very low $(<0.06 \mathrm{ppm})$ in both districts. Furthermore, Vrbic and Stupar [1980] also found a negative correlation between $[\mathrm{Sr}]$ in water with DMFT scores in areas with low $[\mathrm{F}](<0.15 \mathrm{ppm})$.

In addition to the studies investigating a possible link between caries reduction and [Sr] in drinking water, several studies also attempted to establish a similar link for $\mathrm{Sr}$ in surface enamel and/or in plaque. Little and Barrett conducted two studies [1976a, b] investigated possible relationships between $[\mathrm{Sr}]$ and $[\mathrm{F}]$ in surface and near-surface enamel and caries prevalence. Studies were conducted on teeth obtained from lifelong residents of either east or west coast in the USA. Contradicting results were found when teeth were grouped according to DMFT scores of $<3$ or $>7$. In samples from the east coast, both $[\mathrm{Sr}]$ and $[\mathrm{F}]$ were higher in surface and near-surface enamel in low caries teeth, whereas in samples from the west coast, this was only true for [F], with [Sr] being higher in high caries samples. It must be noted that, in general, $[\mathrm{Sr}]$ and $[\mathrm{F}]$ were somewhat higher in west compared 
to east coast samples, although $[\mathrm{Sr}]$ were virtually identical in low caries teeth on east and west coast. The authors explained the east coast-west coast discrepancy with the above-proposed optimum [Sr] as an excess in Sr or lack thereof may increase the tooth's susceptibility to caries. Two comparable studies by Curzon and Losee [1977b, 1978] were able to provide similar results, showing a stronger relationship between [Sr] in whole enamel and lower caries incidence in east than in west coast enamel samples.

Furthermore, Curzon and Losee [1977a] were able to demonstrate that high $[\mathrm{Sr}]$ in enamel were associated with low caries prevalence by studying 147 samples obtained from 59 communities in 19 states in the USA. Other elements, such as F, were not studied. A subsequent study by Spector and Curzon [1979] did involve [Sr] and $[\mathrm{F}]$ analyses. However, the authors were not able to demonstrate a relationship between $[\mathrm{Sr}]$ in surface enamel and DMFT scores. A weak correlation between $[\mathrm{F}]$ and DMFT was found $(\mathrm{r}=-0.16)$ and also between $[\mathrm{Sr}]$ and [F] $(\mathrm{r}=0.48)$. In contradiction, Vrbic and Stupar [1980] were able to demonstrate a negative correlation between [Sr] in enamel and caries incidence, which was supported by the later studies of Athanassouli et al. [1983] and Curzon [1985].

Only very few studies investigated the possible correlation between $\mathrm{Sr}$ in plaque and caries prevalence. Schamschula et al. [1977] reported a negative correlation between $[\mathrm{Sr}$ ] and DMFT $(\mathrm{r}=-0.15)$ in a primitive population in Papua New Guinea ( $\mathrm{n}=301 ; 12-24$ years of age), which, however, was weaker than correlations for [Ca] and $[\mathrm{F}]$. Similar results $(\mathrm{r}=-0.23)$ were obtained by the same group [Schamschula et al., 1978b] when studying 72 children aged 9.7-13 years. Curzon [1985] was also able to demonstrate this relationship $(\mathrm{r}=-0.83)$ in addition to the negative correlations between $[\mathrm{Sr}]$ in water, and in enamel and DMFS scores, reported earlier.

Only two studies on salivary $\mathrm{Sr}$ and caries prevalence could be found. Curzon [1984] was able to demonstrate a weak, negative relationship between $[\mathrm{Sr}]$ in saliva and caries prevalence $(\mathrm{r}=-0.13)$ in 105 children aged 14 years. In contradiction, during one very recent study [Shigemi et al., 2008] on 521 children aged 6-12 years a positive correlation between $[\mathrm{Sr}]$ in saliva and using the author's terminology 'caries experience' (no DMFT/S scores were recorded) was reported. In addition, the authors showed that in groups with high 'fluoride experience rates' (due to $\mathrm{F}$ mouth rinsing at school), $[\mathrm{Sr}]$ in saliva tended to be lower.
In the context of epidemiological studies, it should be mentioned that Curzon and Spector [1977] reported enamel mottling when examining 1,313 children aged $12-14$ years in seven towns in Wisconsin (USA). As water [F] were very similar in the study area (1-1.29 ppm), only a correlation between $[\mathrm{Sr}]$ in water $(0.02-33.9 \mathrm{ppm})$ and mottling scores $(r=0.85)$ could be established, and, interestingly, only in lifelong residents.

Finally, Riyat and Sharma [2010] reported that [Sr] in blood was higher in a group $(\mathrm{n}=15)$ who had no history of caries in comparison to a group $(\mathrm{n}=15)$ with previous caries experience, although only in a relatively small group of subjects. A similar relationship was found for $[\mathrm{F}]$ and [Se].

\section{Sr in Oral Care Products}

Considering the interest in $\mathrm{Sr}$ within the caries research community, it was not surprising that awareness of $\mathrm{Sr}$ was also raised in the oral care industry.

Zero et al. [1982] conducted a series of investigations, perhaps better described as 'product safety studies' as a dentifrice containing not only Sr but also EDTA was evaluated for changes in surface enamel morphology, [Sr] in enamel and enamel solubility. The test dentifrice was compared to a commercially available control dentifrice. No significant changes in surface morphology were noted; however, both products rendered the enamel surface less soluble and $[\mathrm{Sr}]$ in enamel increased in the test but not in the control dentifrice.

It appears that several manufacturers of oral care products were pursuing $\mathrm{Sr}$ as a novel anti-caries agent in the late 1980s. A total of three in situ studies, two enamel fluoride uptake (EFU) studies [Bowman et al., 1988a, b] and one de-/remineralization caries study [Wefel et al., 1995] were reported. All studies evaluated $\mathrm{NaF}$ formulations containing a so-called 'polyampholyte delivery system' (PAA-Sr), which was essentially a combination of a soluble $\mathrm{Sr}$ salt (not specified) and a polyacrylic acid $(\mathrm{MW}=4,500 \mathrm{Da})$. Substantially enhanced EFU values were reported for PAA-Sr, for both mouth rinse [Bowman et al., 1988a] and dentifrice [Bowman et al., 1988b] delivery formats, in comparison to controls with the same [F]. The study by Wefel et al. [1995] was able to demonstrate anti-caries effectiveness of PAA-Sr which was comparable to a 2,800 ppm F (as NaF) control dentifrice. Two studies [Mellberg and Fletcher, 1990; Afflitto et al., 1992] conducted by a direct competitor and comparing PAA-Sr with a different control dentifrice were also reported. The 
study by Mellberg and Fletcher [1990] found comparatively lower EFU in vitro for PAA-Sr. The more comprehensive study by Afflitto et al. [1992] reported comparatively lower salivary $\mathrm{F}$ bioavailability and less cariostatic activity in the rat caries model for PAA-Sr.

A Polish group conducted two in situ studies on experimental dentifrices containing $\mathrm{Sr}+\mathrm{F}$ [Kaczmarek et al., 2005] and Sr-HAp [Surdacka et al., 2007]. Both studies were primarily concerned with investigating the deposition of Sr into artificial white spot lesions, and both studies were able to demonstrate an increase in $[\mathrm{Sr}]$ in enamel after 3 and 6 months of study duration.

Two further studies are worth mentioning here. Nishino [1981] investigated the effect of a $\mathrm{Zn}$-acetate/Sr-acetate/tannic acid mouth rinse on caries reduction in 24 children aged 3-10.3 years and using the Cariostat test. A reduction in 'caries activity' was achieved by this rinse, but due to the study design no Sr effect can be extrapolated. Klinger and Wiedemann [1986] studied the effect of a mineralizing solution containing $\mathrm{Ca}, \mathrm{Sr}, \mathrm{Pi}$ and tartrate in comparison to an amine $\mathrm{F}$ solution on the remineralization of approximal lesions in vivo. The mineral rinse did not induce measureable remineralization, whereas the F solution did.

No reports on potential cariostatic properties of products containing $\mathrm{SrCl}_{2} \times 6 \mathrm{H}_{2} \mathrm{O}(\mathrm{SCH})$, designed for the relief of dentin hypersensitivity, could be retrieved.

\section{Sr in the Oral Cavity}

\section{Sr in Teeth}

A summary of results from various investigators can be found in online supplementary tables 1 (enamel) and 2 (dentin) (for all online supplementary material, see www.karger.com/doi/10.1159/000343008), with similar Sr concentrations reported for both tissues. Regardless of the investigator, study site or analytical technique employed, considerable variations in Sr concentration were found, and especially in enamel.

With the exception of the osteoporosis drug Sr ranelate [for review see Marie et al., 2001], the dentine hypersensitivity treatment agent SCH [for review see Addy and Dowell, 1983] or Sr-containing glass ionomers cements (Sr-GIC) [Kim et al., 2010], diet is the only Sr source for the human body (approx. 2.1-2.4 mg/day) [Schroeder et al., 1972].

Comparatively higher [Sr] were found in enamel of permanent than in deciduous teeth [Cutress, 1972a; Nixon and Helsby, 1976; Shashikiran et al., 2007], whereas
Zaichick and Ovchjarenko [1996] found no differences. To the authors' knowledge, only two studies [Steadman et al., 1958; Lundberg et al., 1965] conducted Sr analyses of enamel from unerupted, permanent teeth, thus assuring that any Sr present would have been incorporated systemically. Both studies reported similar $[\mathrm{Sr}]$ in relation to the enamel of erupted teeth, suggesting that most of the $\mathrm{Sr}$ is incorporated before eruption and that little change in [Sr] in enamel occurs with age. Later studies either supported [Little and Steadman, 1966] or contradicted [Derise and Ritchey, 1974] these findings.

Several studies investigated the distribution of $\mathrm{Sr}$ in enamel with respect to depth and, again, considerable variation was noted. Steadman et al. [1958] found an almost uniform Sr distribution in enamel which was supported by other studies [Vrbic and Stupar, 1980; Noren et al., 1983; Frank et al., 1989], whereas Cutress [1972a] reported either higher surface or higher bulk [Sr] depending on the sample's origin. The concept of a Sr gradient in teeth was also supported by Little and Barrett [1976a, b], who reported higher [Sr] in surface than in bulk enamel.

Strong, positive linear relationships were found between (a) $[\mathrm{Sr}]$ in water and deciduous as well as permanent (bulk) enamel and (b) between $[\mathrm{Sr}]$ and $[\mathrm{F}]$ in water, but only a weak, positive relationship was found between [Sr] and [Ca] in water [Nixon and Helsby, 1976]. However, later studies [Spector and Curzon, 1978; Curzon, 1985] conducted in the USA found only weak, positive correlations between $[\mathrm{Sr}]$ in water and [Sr] in surface enamel. Cutress [1972a] reported positive correlations between $\mathrm{Sr}$ and $\mathrm{Ca}$ and $\mathrm{Sr}$ and $\mathrm{F}$ in surface and near-surface enamel, which was supported for Sr-Ca in general [Noren et al., 1983; Brown et al., 2004] and for Sr-F in surface enamel [Spector and Curzon, 1979].

\section{Sr in Oral Fluids - Plaque and Saliva}

$[\mathrm{Sr}]$ in plaque (online supplementary table 3 ) and saliva (online supplementary table 4 ) exhibited similar variability compared to values reported in teeth, presumably due to environmental and dietary influences. Schamschula et al. [1977] found strong, positive correlations in plaque for $\mathrm{Sr}-\mathrm{Ca}$ and $\mathrm{Sr}-\mathrm{P}$, which was confirmed by further studies [Schamschula et al., 1978a, b]. However, weaker Sr-F and Sr-Mg correlations and no correlation between $[\mathrm{Sr}]$ and the dry weight of plaque were found. Curzon [1984, 1985] reported considerable differences depending on the geographical origin of the donor with plaque and saliva $[\mathrm{Sr}]$ being positively correlated with water $[\mathrm{Sr}]$. Comparatively high $\mathrm{Sr}$ plaque values were report- 
ed by a more recent study [Spets-Happonen et al., 1998], presumably due to dietary Sr [Rytömaa et al., 1975]. In saliva, positive correlations were found for Sr-Ca and Sr$\mathrm{Mg}$, but not for Sr-F [Schamschula et al., 1978a]. By far the highest plaque and the only plaque-fluid $[\mathrm{Sr}]$ were reported by Shields et al. [1984], who found plaque fluid [Sr] of up to $1,570 \mathrm{ppm}$. Study subjects were from an area known for its high drinking water [Sr] of up to $12.3 \mathrm{ppm}$, clearly demonstrating environmental effects of $\mathrm{Sr}$ accumulation in the oral cavity.

\section{Sr and CaPi}

Sr has been shown to be adsorbed by enamel and to a greater extent by dentin and HAp [Hodge et al., 1946]. It is generally assumed that $\mathrm{Sr}$ is incorporated into the crystal lattice of HAp due to the similarity in ionic radii between $\mathrm{Sr}(1.12 \AA)$ and $\mathrm{Ca}(0.99 \AA)$ [Elliott, 1973]. Studies on HAp [Collin, 1959; Likins et al., 1960; Schoenberg, 1963; Koutsoukos and Nancollas, 1981; Markovic and Brecevic, 1992], and monetite [Likins et al., 1959] have shown that precipitates formed in the presence of Ca and Sr had Ca:Sr ratios which were higher than the Ca:Sr ratio in solution, suggesting preferential incorporation in favor of Ca. Collin [1959] also demonstrated that $\mathrm{a}_{0}$ and $\mathrm{c}_{0}$ lattice constants increase linearly with $\mathrm{Sr}$ substitution, which was supported by other studies [Lagergren and Carlström, 1957; Schoenberg, 1963; LeGeros et al., 1977; Okayama et al., 1991; Markovic and Brecevic, 1992]. Pan et al. [2009b] studied HAp nucleation from simulated body fluid in the presence of various $[\mathrm{Sr}]$ and found that only $[\mathrm{Sr}] \geq 0.3 \mathrm{mM}$ (at $[\mathrm{Ca}]=2.5 \mathrm{mM}$ ) Induce the formation of Sr-HAp, whereas no Sr was detected in HAp formed at $[\mathrm{Sr}] \leq 0.1 \mathrm{mM}$, highlighting some sort of a threshold [Sr], or perhaps more importantly a threshold $\mathrm{Sr}$ :Ca ratio. While Sr incorporation into HAp is limited to a few $\mathrm{mol} \%$, Sr is more favorably substituted in OCP than in HAp, thus stabilizing this HAp precursor phase [Matsunaga and Murata, 2009].

In addition to the incorporation of Sr into the crystal lattice, several studies [Dedhiya et al., 1973, 1974] reported the formation of surface $\mathrm{Sr}$ complexes, approximately oneunit-cellthick, with theformulae ofCa $\mathrm{Sr}_{4}\left(\mathrm{PO}_{4}\right)_{6}(\mathrm{OH})_{2}$ in the absence of $\mathrm{F}$, and $\mathrm{Ca}_{6} \mathrm{Sr}_{4}\left(\mathrm{PO}_{4}\right)_{6} \mathrm{~F}_{2}$ in the presence of F. These complexes were shown to form in the presence of $\mathrm{Sr}$ (and F) and under conditions resembling cariogenic attacks. A later study by Stranick and Root [1991] suggested the formation of a surface apatitic phase with a $\mathrm{Sr}$ :Ca ratio of 3.4:6.6 and an increase in surface SrFAp formation with increasing [Sr]. Investigations into the metastable equilibrium solubility behavior of carbonated HAp by Heslop et al. [2004, 2005] supported earlier investigations by Dedhiya et al. [1973], but only for solution Sr:Ca ratios $>1.5$. At Sr:Ca ratios $<2 / 3$, however, the stoichiometry yielding metastable equilibrium solubility data superpositioning was found to be that of HAp.

Bachra and Fischer [1969] reported that Sr can slow down HAp crystal growth, which was supported by other studies for HAp [Koutsoukos and Nancollas, 1981; Christoffersen et al. 1997; Verberckmoes et al., 2004], for ACP [Root, 1990; Hidaka et al., 1991], for ACP to OCP to HAp conversions [Markovic and Brecevic, 1992], and for $\alpha$-tricalcium phosphate to HAp conversion [Boanini et al., 2010]. Bigi et al. [1988] suggested that Sr does not 'greatly affect' the conversion of OCP and BR into HAp, and to a lesser extent than $\mathrm{Mg}$. Sr can, however, also be seen to stabilize HAp precursor phases [Matsunaga and Murata, 2009] and therefore to increase the number of biological nucleation sites [Drouet et al., 2008]. Pan et al. [2009b] also postulated that nucleation of Sr-HAp is easier than that of HAp, and that this may act as a template for HAp growth. This would explain the results of Thuy et al. [2008], who demonstrated enhanced in vitro remineralization of caries lesions in the presence of $\mathrm{Sr}$ and F compared to F alone.

Since the incorporation of Sr into the lattice somewhat distorts the crystallinity and leads to an expansion of the crystallite, the incorporation of elements with smaller ionic radii is therefore possible [Lappalainen and Knuuttila, 1982]. Li et al. [2007] studied Sr-HAp prepared with different $[\mathrm{Sr}]$ and found considerably higher $\left[\mathrm{CO}_{3}\right]$ with increasing $[\mathrm{Sr}]$ in $\mathrm{Sr}-\mathrm{HAp}$. Vice versa, a greater ability of carbonated in comparison to non-carbonated HAp to 'fix' Sr was found by Drouet et al. [2008]. In addition, Featherstone and Nelson [1980] as well as Nelson et al. [1982] reported that Sr can at least partially offset the paracrystalline disorder in HAp induced by carbonate, and $\mathrm{Sr}$ and $\mathrm{F}$ in combination were shown to improve the crystallinity of carbonated HAp to a greater extent than by $\mathrm{Sr}$ or F alone, suggesting synergistic effects between $\mathrm{Sr}$ and $\mathrm{F}$ in low-carbonated HAp, which is very similar to enamel [Featherstone et al., 1983]. Earlier investigations by Featherstone et al. [1981] postulated that $\mathrm{Sr}$ (or $\mathrm{Zn}$ ) is incorporated into Ca-deficient areas of enamel, which were related to carbonate inclusion. LeGeros et al. [1988] showed that the simultaneous presence of $\mathrm{F}$ and $\mathrm{Sr}$ will negate the otherwise negative impact of $\mathrm{Sr}$ on the formation and stability of HAp, presumably due to simultaneous substitution of $\mathrm{Sr}$ for $\mathrm{Ca}$ and of $\mathrm{F}$ for $\mathrm{OH}$ [LeGeros et 
al., 1977; Stranick and Root, 1991]. It has also been reported that greater Sr-HAp incorporation is possible in the presence of F [LeGeros et al., 1988] or monofluorophosphate [Stranick and Root, 1991].

Considering the aforementioned effects of Sr incorporation into the crystal lattice, it is not surprising that SrHAp [Saleeb and DeBruyn, 1972] or partially substituted Sr-HAp [LeGeros et al., 1988; LeGeros, 1990; Okayama et al., 1991; Christoffersen et al., 1997; Verberckmoes et al., 2004; Pan et al., 2009a] have been shown to be more soluble than HAp, and that even a Sr for Ca substitution at $1 \mathrm{~mol} \%$ drastically increased HAp dissolution rates [Pan et al., 2009a]. Similar results were obtained for Sr-substituted carbonated HAp and fluoridated HAp by LeGeros [1990]; however, Featherstone et al. [1983] reported synergistic effects between $\mathrm{Sr}$ and $\mathrm{F}$ in reducing the dissolution of low- and high-carbonated HAp when incorporated into the HAp crystals.

\section{Discussion}

When studying the (primarily dental) literature concerned with Sr and caries or caries-related areas, two facts are apparent: the lack of randomized controlled trials and the level of discrepancy in the literature in general. To understand potential Sr effects on decreasing caries prevalence, several questions must and will be answered: (1) How and where does Sr accumulate in the oral cavity? (2) What are the effects of Sr incorporation into the dental hard tissues? (3) How does solution $\mathrm{Sr}$ affect CaPi dissolution, formation or transformation? (4) Does Sr exhibit antimicrobial activity?

It has been established by many investigators that $\mathrm{Sr}$ is present in enamel, dentin, saliva and plaque. [Sr] have been found to vary considerably (online supplementary tables 1-4), and it is safe to assume that both the geographical origin of the sample (i.e. the direct result of the [Sr] in soil and water) and diet are accountable for these differences. Sampling techniques, sample preparation and analyses can add further error [e.g. Curzon, 1984]. In enamel, not only overall [Sr] but also its distribution was found to vary considerably [Rytömaa et al., 1975] and Sr gradients in enamel have been reported by several researchers, with higher [Sr] found in surface than in bulk enamel [Little and Barrett, 1976a, b]. Again, it is safe to assume that both topical and systemic effects are involved in $\mathrm{Sr}$ accumulation in the dental hard tissues, and especially in enamel. Animal studies have shown that $\mathrm{Sr}$ causes disturbances in ameloblast morphology and amelogenesis

Critical Review on Strontium and Its Role in Caries
[Weinmann, 1943; Neiman and Eisenmann, 1975], whereas several reports exist on Sr-mediated dentin hypomineralization [e.g. Yaeger and Eisenmann, 1963]. In humans, information is limited to one epidemiological study [Curzon and Spector, 1977] which established a link between $[\mathrm{Sr}]$ in water and enamel mottling, but only for lifelong residents, thus indicating that $\mathrm{Sr}$ can affect amelogenesis and is actually incorporated into the dental hard tissues during their formation. Several laboratory studies [e.g. Neumann et al., 1963] have shown that Sr can be incorporated into the (carbonated) HAp crystal lattice, substituting for $\mathrm{Ca}$. In addition, Sr surface complexes were proposed to form during HAp dissolution in the presence of $\mathrm{Sr}$, suggesting a different form of $\mathrm{Sr}$ accumulation [Dedhiya et al., 1973, 1974]. At present, however, only one report exists on the mineral phase associated with $\mathrm{Sr}$ in enamel in vivo. Although LeGeros et al. [1977] found apatitic phases only in enamel with varying [Sr], the relationship between lattice parameters and [Sr] was not strong, suggesting that $\mathrm{Sr}$ was associated with enamel in another form. Furthermore, as $\mathrm{Sr}$ was shown to stabilize HAp precursor phases [Matsunaga and Murata, 2009] and to slow down HAp conversion [e.g. Markovic and Brecevic, 1992], it cannot be excluded that $\mathrm{Sr}$ is present in enamel or dentin, and possibly exclusively, in a non-apatitic $\mathrm{CaPi}$ phase. This is further supported by the Sr discrimination during HAp formation [e.g. Collin, 1959], which is not, however, the case for other CaPi phases, such as OCP [Matsunaga and Murata, 2009]. Driessens [1982, 1986] suggested that $\mathrm{Sr}$ is associated with whitlockite $(\mathrm{WH})\left[\mathrm{Ca}_{10}\left(\mathrm{HPO}_{4}\right)\right.$ $\left(\mathrm{PO}_{4}\right)_{6}$ ], a CaPi phase not normally found in enamel. As no direct proof can be provided for apatitic or non-apatitic Sr phases in enamel and dentin, further research is clearly needed in this area.

If the accumulation of $\mathrm{Sr}$ in enamel during amelogenesis leaves several questions unanswered, post-eruptive $\mathrm{Sr}$ accumulation in (surface) enamel is equally poorly understood, especially when the mineral phase with which $\mathrm{Sr}$ is associated is considered. Several epidemiological studies [e.g. Spector and Curzon, 1978] have clearly shown a positive correlation between $[\mathrm{Sr}]$ in water and surface enamel. Based on the aforementioned laboratory experiments, whether or not Sr replaces Ca in the HAp lattice can only be speculated upon, as other forms of accumulation or adsorption, as shown for F [White et al., 1994], have not (yet) been reported. The fact that $\mathrm{Sr}$ can easily substitute for Ca in enamel can be explained as carbonate (one of the major impurities in enamel) expands the HAp crystal lattice and therefore allows ions with bigger ionic radii than $\mathrm{Ca}$ (such as $\mathrm{Sr}$ ) to enter and substitute for $\mathrm{Ca}$ [Nelson et al., 
1982]. At the same time, Sr incorporation into the lattice allows for better F-OH substitution [Featherstone et al., 1983]. Does this mean there is a synergistic accumulation of Sr and F? Although plausible, this theory cannot currently be supported, primarily because previous studies [e.g. Steadman et al., 1958] have failed to show associations between $\mathrm{Sr}$ and $\mathrm{F}$. The potential consequences of these lattice substitutions have been studied by many investigators. Although there is some discrepancy, the majority of the literature supports the proposition that Sr incorporation into (carbonated) HAp increases its solubility, and that F greatly minimizes but not fully mitigates the negative effect of Sr [e.g. LeGeros, 1990].

Few reports exist on potential antimicrobial effects of $\mathrm{Sr}$, and based on the current literature, it can be concluded that $\mathrm{Sr}$ does not exhibit antimicrobial properties at the [Sr] found in saliva and, more importantly, plaque (hence, the relevant literature is not discussed).

Considering what has been discussed so far, it appears that $\mathrm{Sr}$ is more likely to show caries-potentiating rather than -preventing effects. How can the results of the numerous animal caries and epidemiological studies, which, according to the authors show caries-preventative effects (even though strongly [Sr]-dependent) be explained? As pointed out earlier, animal caries studies are a good, but by no means complete, surrogate for caries studies in humans. Therefore, their findings should be regarded with some caution. Nonetheless, the results of several studies do mirror the findings of epidemiological studies, at least to some extent. Sr effects were observed in the presence or absence of F, and 'optimum' [Sr] were seen in most studies. In this context, it must be mentioned that animal caries studies often give rise to mis- or at least overinterpretation as caries scores are rarely combined (no DMFS/ DMFT etc. equivalent exists), leaving the authors no other option than to concentrate on one particular site of occurrence where observed caries reductions were in line with what the authors may have hoped for. The present authors found at least one study where this biased practice of 'cherry picking' led to misinterpretation of data. Nonetheless, the observed reduction in caries is compelling, and even more so as an 'optimum' [Sr] was proposed.

The results of several epidemiological studies are presented in figure 1. In agreement with the rat caries studies, a $[\mathrm{Sr}]$-dependent reduction in caries was observed with an optimum [Sr] of approximately $5-10 \mathrm{ppm}$ in water. However, four facts must be mentioned in this context: (a) [F] in water in all study areas was approximately $1 \mathrm{ppm}$; (b) no correlations with other trace elements were conducted by the authors; (c) the results of immigrants show a completely different $[\mathrm{Sr}]$ caries prevalence pattern compared to lifelong residents; (d) sadly, none of the studies were concerned with caries risk factors, such as socioeconomic status and dietary habits. With regards to (c) it is difficult to judge whether these effects were causative or co-incidental as the study population was relatively small (as low as 22 subjects in one of the towns), not to mention that no information was provided about the caries histories of the subjects, their oral care or dietary habits. This, however, can also be made as a general comment about the presented epidemiological studies, making it difficult and perhaps impossible to extract any meaningful conclusions from them. Considering (b), this is perhaps the greatest weakness of most epidemiological studies concerned with Sr. Early studies [e.g. Losee and Adkins, 1968, 1969] suggested that perhaps not $\mathrm{Sr}$ alone is associated with the observed caries reduction, whereas later studies were solely concerned with Sr. In more than one study, the present authors would have been able to 'make a case' for B or Fe as similar relationships compared to Sr were found for these trace elements and caries reduction. In relation to this suggestion it is perhaps time to review the role of trace elements in general (and not just $\mathrm{Sr}$ ) in relation to caries - again, as the latest review (published in English) that could be retrieved dates back to 1987. In more than one previous review [e.g. Curzon and Crocker, 1978], it was concluded that apart from F and $\mathrm{Sr}$, other trace elements, such as $\mathrm{Al}, \mathrm{Fe}$ and Se, also exhibit negative correlations with caries prevalence. In relation to (a) it must be noted that two epidemiological studies [Athanassouli et al., 1983; Vrbic and Stupar, 1980] were reported, correlating [Sr] with a decrease in caries in areas with negligible $[\mathrm{F}]$ in water. The criticism by LeGeros [1990], that the 'possible 'cariostatic' effect of Sr ... may be due principally to the effect of $F$ which was simultaneously present', is therefore not entirely justified.

Overall, it must be noted that the available literature on Sr and its role in caries prevention, despite its many flaws, discrepancies and the lack of randomized controlled trials, is compelling to say the least. One particular aspect, the 'optimum' [Sr], noted more than once, is especially interesting. So far, only Driessens [1982, 1986] has provided a hypothesis for this phenomenon, which will now be discussed. It is worth mentioning that his hypothesis is, strangely, ignored by the research community, as the present authors were not able to retrieve a single article even presenting his reasoning. Driessens $[1982,1986]$ proposed that $\mathrm{Sr}$ is incorporated into $\mathrm{WH}$ rather than an apatitic phase during tooth formation. As Sr stabilizes $\mathrm{WH}$ it renders it less susceptible to acid attack. Mg, one of 
the major impurities in enamel-HAp and present at $[\mathrm{Mg}]$ between 0.21 and $0.44 \%$, is also strongly associated with $\mathrm{WH}$. The introduction of Sr decreases the solubility of $\mathrm{Mg}-\mathrm{WH}$, without increasing the amount of that phase in relation to enamel-HAp. This would only explain the generally noted reduction in susceptibility to caries in rat caries studies. Considering the 'optimum' [Sr], Driessens [1982] hypothesized that when Sr is in excess, the WH phase would be extended at the expense of the less soluble enamel-HAp phase, therefore rendering the enamel more susceptible to caries at elevated [Sr]. Although only a hypothesis, it is the sole explanation proposed for the 'optimum' [Sr] observed in many studies so far. Whereas Driessens suggested that $\mathrm{Sr}$ exhibits its cariostatic properties only pre-eruptively, the data presented here do not support this, although stronger pre- than post-eruptive effects were noted in rat caries studies (table 1).

For the moment, the thought that a $[\mathrm{Sr}]$ in water of 5-10 ppm in the presence of $1 \mathrm{ppm} F$ would present an optimum concentration of both trace elements in caries prevention is entertained. How could this be implemented and what are the practicalities? Water fluoridation is considered 'a relevant and valid choice as a population measure for the prevention of dental caries' [Parnell et al., 2009], although this is only practiced in some countries, and then only after lengthy debate, mainly due to concerns about fluorosis. The opposition to Sr enrichment of drinking water is therefore unthinkable as, unlike for F, no clear evidence exists for its possible caries-preventative efficacy; the present data on Sr simply do not allow for any 'final' conclusions to be drawn.

$\mathrm{Sr}$ can also be found in dentifrices designed for the relief of dentin hypersensitivity. However, no information about the relative anti-caries benefits of these products, which often contain F at approximately $1,000 \mathrm{ppm}$, could be retrieved. These products typically contain $10 \%(w / w)$ $\mathrm{SCH}$, which, at a twice daily application of $1.5 \mathrm{~g}$, would result in a total $\mathrm{Sr}$ dose of $100 \mathrm{mg}$ per day. Although a somewhat flawed comparison, this is similar to the proposed 'optimum' [Sr] as a consumption of 21 of water at a [Sr] of $10 \mathrm{ppm}$ would result in a daily $\mathrm{Sr}$ dose of $20 \mathrm{mg}$ alone, not taking into account other Sr sources. Information on these products would therefore be beneficial, as some anti-caries benefits of Sr-containing dentifrices and mouthwashes, although not commercially available anymore, have been reported [Bowman et al., 1988a, b; Wefel et al., 1995]. Furthermore, the addition of Sr to oral care products would perhaps provide an opportunity to increase oral $\mathrm{F}$ retention. Unlike $\mathrm{Ca}, \mathrm{Sr}$ can be formulated in the presence of $\mathrm{F}$ without greatly reducing $\mathrm{F}$ bio- availability, as $\mathrm{SrF}_{2}$ is 77 times more soluble than $\mathrm{CaF}_{2}$ $\left(\mathrm{KSP}_{\mathrm{SrF}_{2}}=3 \times 10^{-9} ; \mathrm{KSP}_{\mathrm{CaF}_{2}}=3 \times 10^{-11}\right)$ [Cameron et al., 1961]. The overall benefits of Ca pre-rinses on increasing oral F retention have been shown in many studies [e.g. Vogel et al., 2006], and $\mathrm{Sr}+\mathrm{F}$ rinses would be expected to show a similar potential due to the similarity between $\mathrm{Ca}$ and $\mathrm{Sr}$ and the earlier reported possibility to accumulate $\mathrm{Sr}$ in plaque through environmental means, thus reducing the number of rinses to one and therefore increasing compliance (providing commercialization of these products). However, further research is necessary to prove these hypotheses and the suggestion that an increase in [Sr] in plaque (fluid) is directly correlated with the ability of plaque to acquire more $\mathrm{F}$.

Finally, the present authors were somewhat surprised by the current lack of interest in $\mathrm{Sr}$ and caries in the dental research community as the related caries research has come to an almost standstill over the last 10 years. Considering the many unanswered questions and the phenomenon that an 'optimum' [Sr] for caries prevention may exist, the lack of interest is rather puzzling. In view of the long and complicated relationship between $\mathrm{Sr}$ and caries, is it now time to 'file for divorce'? To put it simply, no, not yet.

\section{Conclusions}

Sr has exhibited some cariostatic properties in the majority of animal caries and epidemiological studies reported to date. The results of several epidemiological studies (fig. 1) led investigators to suggest (and almost believe in) an 'optimum' [Sr] in water. However, no definite proof of the role of $\mathrm{Sr}$ in caries prevention or the existence of an 'optimum' $[\mathrm{Sr}$ ] can be provided based on the current data, mainly due to the lack of randomized controlled trials and insufficient information provided in the epidemiological studies. A thorough understanding of the role of $\mathrm{Sr}$ in caries prevention is therefore required, especially regarding its association with the dental hard tissues, plaque and plaque fluid and the mineral phases involved. Furthermore, associations between F, Ca and $\mathrm{Sr}$ in the oral cavity need to be investigated.

\section{Acknowledgments}

The authors would like to thank the reviewers for their invaluable contributions to the structure and content of this review, and Dr. R.J.M. Lynch for the help provided in the preparation of the manuscript. 


\section{References}

-Addy M, Dowell P: Dentine hypersensitivity - a review. Clinical and in vitro evaluation of treatment agents. J Clin Periodontol 1983;10: 351-363.

Adkins BL, Losee FL: A study of the covariation of dental caries prevalence and multiple trace element content of water supplies. N Y State Dent J 1970;36:618-622.

Afflitto J, Schmid R, Esposito A, Toddywala R, Gaffar A: Fluoride availability in human saliva after dentifrice use: correlation with anticaries effects in rats. J Dent Res 1992;71 (Spec Iss):841-845.

-Ahlberg M, Akselsson R: Proton-induced x-ray emission in trace analysis of human tooth enamel and dentine. Int J Appl Radiat lsot 1976;27:279-290.

-Anderson RJ: Dental caries prevalence in relation to trace elements. Br Dent J 1966;120: 271-275.

-Anonymous: Strontium, other trace elements and dental caries. Nutr Rev 1978;36:334-337.

Anttila A: Proton-induced X-ray emission analysis of $\mathrm{Zn}, \mathrm{Sr}$ and $\mathrm{Pb}$ in human deciduous tooth enamel and its relationship to dental caries scores. Arch Oral Biol 1986;31:723726.

Appleton J: The structure of dentin after the injection of strontium chloride by backscattered electron imaging in the scanning electron microscope. Arch Oral Biol 1993;38: $1-4$.

Arwill T, Myrberg N, Soremark R: The concentration of $\mathrm{Cl}, \mathrm{Na}, \mathrm{Cu}, \mathrm{Sr}$, and $\mathrm{Mn}$ in human mixed saliva. Odontol Revy 1967;18:1-6.

-Ashrafi MH, Spector PC, Curzon ME: Pre- and posteruptive effects of low doses of strotium on dental caries in the rat. Caries Res 1980 14:341-346

-Athanassouli TM, Papastathopoulos DS, Apostolopoulos AX: Dental caries and strontium concentration in drinking water and surface enamel. J Dent Res 1983;62:989-991.

Bachra BN, Fischer HR: The effect of some inhibitors on the nucleation and crystal growth of apatite. Calcif Tissue Res 1969;3:348-357.

Beaton GH: Strontium and dental caries. Nutr Rev 1983;41:342-344.

Bigi A, Gazzano M, Ripamonti A, Roveri N: Effect of foreign ions on the conversion of brushite and octacalcium phosphate into hydroxyapatite. J Inorg Biochem 1988;32:251257.

-Boanini E, Panzavolta S, Rubini K, Gandolfi M, Bigi A: Effect of strontium and gelatin on the reactivity of alpha-tricalcium phosphate. Acta Biomater 2010;6:936-942.

-Bowen WH, Velez H, Aguila M, Velasquez H, Sierra LI, Gillespie G: The microbiology and biochemistry of plaque, saliva, and drinking water from two communities with contrasting levels of caries in Colombia, S.A. J Dent Res 1977;56(Spec Iss):C32-C39.
Bowman WD, Evans MD, Wietfeldt JR, Faller RV, Agricola FO, Schemehorn BR, Stookey GK, Dunipace AJ, White DJ: In situ fluoride uptake from $0.05 \%$ neutral $\mathrm{NaF}$ mouthrinses: effects of a novel enhanced delivery system. Am J Dent 1988a;1:113-117.

Bowman WD, Wietfeldt JR, Faller RV, Agricola FO, Schemehorn BR, Stookey GK, White DJ: In situ fluoride uptake from $\mathrm{NaF}$ dentifrices: dose response and effects of a novel enhanced delivery system. Am J Dent 1988b;1: 105-111.

Brown CJ, Chenery SRN, Smith B, Mason C, Tomkins A, Roberts GJ, Sserunjogi L, Tiberindwa JV: Environmental influences on the trace element content of teeth - implications for disease and nutritional status. Arch Oral Biol 2004;49:705-717.

-Brudevold F, Reda A, Aasenden R, Bakhos Y: Determination of trace elements in surface enamel of human teeth by a new biopsy procedure. Arch Oral Biol 1975;20:667-673.

Büttner W: Trace elements and dental caries in experiments on animals. Caries Res 1969;3:113.

Calonius PE, Visapaeae A: The inorganic constituents of human teeth and bone examined by $\mathrm{x}$-ray emission spectrography. Arch Oral Biol 1965;10:9-13.

Cameron SA, Heil JM, Holmes OG: Incorporation of strontium into precipitates of calcium fluoride and calcium phosphate. Can J Med Technol 1961;23:28-29.

Castillo Mercado R, Bibby BG: Trace element effects on enamel pigmentation, incisor growth and molar morphology in rats. Arch Oral Biol 1973;18:629-635.

Christoffersen J, Christoffersen MR, Kolthoff N, Barenholdt O: Effects of strontium ions on growth and dissolution of hydroxyapatite and on bone mineral detection. Bone 1997; 20:47-54.

Collin RL: Strontium-calcium hydroxyapatite solid solutions: preparation and lattice constant measurements. J Am Chem Soc 1959; 81:5275-5278.

Collin RL: Precipitate formation in the strontium-phosphate system. Science 1966;151 1386-1388.

Curzon ME: Combined effect of trace elements and fluoride on caries: changes over ten years in northwest Ohio (U.S.A.). J Dent Res 1983; 62:96-99.

Curzon ME: Strontium concentrations in whole human saliva. Arch Oral Biol 1984;29:211214.

Curzon ME: The relation between caries prevalence and strontium concentrations in drinking water, plaque, and surface enamel. J Dent Res 1985;64:1386-1388.

Curzon ME: Effects of a combination of strontium and fluoride on dental caries in the rat. Nutr Res 1988;8:321-326.
Curzon ME, Adkins BL, Bibby BG, Losee FL: Combined effect of trace elements and fluorine on caries. J Dent Res 1970;49:526-528.

Curzon ME, Ashrafi MH, Spector PC: Effects of strontium administration on rat molar morphology. Arch Oral Biol 1982;27:667-671.

Curzon ME, Crocker DC: Relationships of trace elements in human tooth enamel to dental caries. Arch Oral Biol 1978;23:647-653.

Curzon ME, Losee FL: Strontium content of enamel and dental caries. Caries Res 1977a;11:321-326.

Curzon ME, Losee FL: Dental caries and trace element composition of whole human enamel: Eastern United States. J Am Dent Assoc 1977b;94:1146-1150.

Curzon ME, Losee FL: Dental caries and trace element composition of whole human enamel: Western United States. J Am Dent Assoc 1978;96:819-822.

Curzon ME, Losee FL, Macalister AD: Trace elements in the enamel of teeth from New Zealand and the USA. NZ Dent J 1975;71:80-83.

Curzon ME, Spector PC: Enamel mottling in a high strontium area of the U.S.A. Community Dent Oral Epidemiol 1977;5:243-247.

Curzon ME, Spector PC: Strontium uptake by rat enamel from various strontium salts. Dent Res 1980;59:1988.

Curzon ME, Spector PC: Effect of using different strontium salts on dental caries in the rat Caries Res 1981;15:296-301.

Curzon ME, Spector PC, Iker HP: An association between strontium in drinking water supplies and low caries prevalence in man. Arch Oral Biol 1978;23:317-321.

Cutress TW: The inorganic composition and solubility of dental enamel from several specified population groups. Arch Oral Biol 1972a;17:93-109.

Cutress TW: Composition, flow rate and $\mathrm{pH}$ of mixed and parotid salivas from trisomic 21 and other mentally retarded subjects. Arch Oral Biol 1972b;17:1081-1094.

Dedhiya MG, Young F, Higuchi WI: Mechanism for the retardation of the acid dissolution rate of hydroxapatite by strontium. J Dent Res 1973;52:1097-1109.

Dedhiya MG, Young F, Higuchi WI: Mechanism of hydroxyapatite dissolution. Synergistic effects of solution fluoride, strontium, and phosphate. J Phys Chem 1974;78:1273-1279.

Derise NL, Ritchey SJ: Mineral composition of normal human enamel and dentin and the relation of composition to dental caries. II. Microminerals. J Dent Res 1974;53:853-858.

-Dreizen S, Levy BM, Niedermeier W, Griggs $\mathrm{JH}$ : Comparative concentrations of selected trace metals in human and marmoset saliva. Arch Oral Biol 1970;15:179-188.

Driessens FC: Strontium and caries; in Myers HM (ed): Monographs in Oral Science, Vol. 10: Mineral Aspects of Dentistry. Basel, Karger, 1982, pp 148-153. 
Driessens FC: Enamel caries and strontium; in Helsby CA: Determination of strontium in huDriessens FC, Wöltgens JHM (eds): Tooth Development and Caries, Vol. II. Boca Raton, CRC Press, 1986, pp 115-129.

Drouet C, Carayon MT, Combes C, Rey C: Surface enrichment of biomimetic apatites with biologically active ions $\mathrm{Mg}^{2+}$ and $\mathrm{Sr}^{2+}$ : a preamble to the activation of bone repair materials. Mat Sci Eng C Biomimetic Supramol Sys 2008;28:1544-1550.

-Eisenmann DR, Yaeger JA: Alterations in the formation of rat dentine and enamel induced by various ions. Arch Oral Biol 1969;14: 1045-1064.

Eisenmann DR, Yaeger JA: In-vitro mineralization of hypomineralized dentine induced by strontium and fluoride in the rat. Arch Oral Biol 1972;17:987-999.

Elliott JC: The problems of the composition and structure of the mineral components of the hard tissues. Clin Orthop Relat Res 1973;93: 313-345.

Ericsson Y: Some differences between human and rodent saliva of probable importance for the different species reactions to cariogenic and cariostatic agents. Arch Oral Biol 1962; 7(suppl 1):327-336.

-Featherstone JD, Nelson DGA: The effect of fluoride, zinc, strontium, magnesium and iron on the crystal-structural disorder in synthetic carbonated apatites. Aust J Chem 1980;33:2363-2368.

-Featherstone JD, Nelson DGA, McLean JD: An electron microscope study of modifications in defective regions of dental enamel and synthetic apatites. Caries Res 1981;15:278288.

Featherstone JD, Shields CP, Khademazad B, Oldershaw MD: Acid reactivity of carbonated apatites with strontium and fluoride substitutions. J Dent Res 1983;62:1049-1053.

-Frank RM, Sargentini-Maier ML, Turlot JC, Leroy $\mathrm{MJ}$ : Zinc and strontium analyses by energy dispersive X-ray fluorescence in human permanent teeth. Arch Oral Biol 1989;34: 593-597.

Frostell G, Larsson SJ, Lodding A, Odelius H, Petersson LG: SIMS study of element concentration profiles in enamel and dentin. Scand J Dent Res 1977;85:18-21.

-Gedalia I, Anaise J, Laufer E: Effect of prenatal, preeruptive, and posteruptive strontium administration on dental caries in hamster molars. J Dent Res 1975;54:1240.

Grady JE, Yaeger JA: Polarizing microscopy of abnormal dentine produced by injections of strontium or fluoride. Arch Oral Biol 1965 10:175-178.

Haldi J, Wynn W, Law ML, Bentley KD: pH on the teeth of albino rats under various conditions conducive to dental caries. Arch Oral Biol 1960;2:46-56.

-Hardwick JL, Martin CJ: A pilot study using mass spectrometry for the estimation of the trace element content of dental tissues. Helv Odontol Acta 1967;11:62-70. man tooth enamel by atomic absorption spectrometry. Anal Chim Acta 1974;69:259265.

Helsby CA: Determination of strontium in human tooth enamel by flameless atomic absorption spectrometry. Talanta 1977;24:4648.

Heslop DD, Bi Y, Baig AA, Higuchi WI: Metastable equilibrium solubility behavior of carbonated apatite in the presence of solution strontium. Calcif Tissue Int 2004;74:72-85.

- Heslop DD, Bi Y, Baig AA, Otsuka M, Higuchi WI: A comparative study of the metastable equilibrium solubility behavior of high crystallinity and low-crystallinity carbonated apatites using $\mathrm{pH}$ and solution strontium as independent variables. J Colloid Interface Sci 2005;289:14-25.

Hidaka S, Abe K, Liu SY: A new method for the study of the formation and transformation of calcium phosphate precipitates: effects of several chemical agents and Chinese folk medicines. Arch Oral Biol 1991;36:49-54.

Hodge HC, Gavett E, Thomas I: The adsorption of strontium at forty degrees by enamel, dentin, bone, and hydroxyapatite as shown by the radioactive isotope. J Biol Chem 1946; 163:1-6.

Hunt CE, Navia JM: Pre-eruptive effects of Mo, $\mathrm{B}, \mathrm{Sr}$ and $\mathrm{F}$ on dental caries in the rat. Arch Oral Biol 1975;20:497-501.

Irving JT, Weinmann JP: Experimental studies in calcification. J Dent Res 1948;27:669-680.

Johansen E, Hein JW: Effect of strontium chloride on experimental caries in syrian hamsters. J Dent Res 1953;32:703.

Johnson AR: X-ray diffraction patterns of rat incisor tooth enamel with a low or high strontium content. J Dent Res 1967;46:79-81.

Johnson AR, Armstrong WD, Singer L: Strontium incorporation into dental enamel. Science 1966;153:1396-1397.

Johnson AR, Armstrong WD, Singer L: The solubility of the mineral phase in the rat of powdered bone and dentine laden with strontium. Arch Oral Biol 1970;15:401-409. study of rat incisor teeth with low or high concentrations of strontium. Arch Oral Biol 1967;12:389-399.

Joseph M, Gedalia I, Fuks A: Effect of strontium and fluoride administration on caries resistance of hamster molars. J Dent Res 1977;56: 924.

Kaczmarek E, Surdacka A, Matthews-Brzozowska T, Miskowiak B: Digital image analysis and visualization of early caries changes in human teeth. Mater Sci Poland 2005;23:551558.

Keyes PH: Dental caries in the molar teeth of rats: II. A method for diagnosing and scoring several types of lesions simultaneously. J Dent Res 1958;37:1088-1099.
Johnson AR, Singer L: An electron microprobe
Kim YK, Yiu CK, Kim JR, Gu L, Kim SK, Weller RN, Pashley DH, Tay FR: Failure of a glass ionomer to remineralize apatite-depleted dentin. J Dent Res 2010;89:230-235.

- Klinger HG, Wiedemann W: Enhancement of in-vivo remineralization of approximal initial caries in man by an organic and inorganic remineralization agent. Arch Oral Biol 1986;31:269-272.

Koutsoukos PG, Nancollas GH: Influence of strontium ion on the crystallization of hydroxyapatite from aqueous solution. J Phys Chem 1981;85:2403-2408.

Lagergren C, Carlström D: Crystallographic studies of calcium and strontium hydroxyapatite. Acta Chem Scand 1957;11:545-550.

-Lappalainen R, Knuuttila M: Atomic absorption spectrometric evidence of relationships between some cationic elements in human dentine. Arch Oral Biol 1982;27:827-830.

LeGeros RZ: Chemical and crystallographic events in the caries process. J Dent Res 1990; 69(Spec Iss):567-574; discussion 634-636.

- LeGeros RZ, Kijkowska R, Jia W, LeGeros JP: Fluoride-cation interactions in the formation and stability of apatites. J Fluor Chem 1988;41:53-64.

LeGeros RZ, Miravite MA, Quirolgico GB, Curzon ME: The effect of some trace elements on the lattice parameters of human and synthetic apatites. Calcif Tissue Res 1977; 22(suppl):362-367.

Li ZY, Lam WM, Yang C, Xu B, Ni GX, Abbah SA, Cheung KMC, Luk KDK, Lu WW: Chemical composition, crystal size and lattice structural changes after incorporation of strontium into biomimetic apatite. Biomaterials 2007;28:1452-1460.

- Likins RC, McCann HG, Posner AS, Scott DB: Comparative fixation of calcium and strontium by synthetic hydroxyapatite. J Biol Chem 1960;235:2152-2156.

- Likins RC, Posner AS, Kunde ML, Craven DL: Comparative metabolism of calcium and strontium in the rat. Arch Biochem Biophys 1959;83:472-481.

Likins RC, Posner AS, Paretzkin B, Frost AP: Effect of crystal growth on the comparative fixation of $\mathrm{Sr} 89$ and Ca 45 by calcified tissues. J Biol Chem 1961;236:2804-2806.

Little MF, Barrett K: Trace element content of surface and subsurface enamel relative to caries prevalence of the west coast of the United States of America. Arch Oral Biol 1976a;21:651-657.

Little MF, Barrett K: Strontium and fluoride content of surface and inner enamel versus caries prevalence in the Atlantic coast of the United States of America. Caries Res 1976b;10:297-307.

Little MF, Steadman LT: Chemical and physical properties of altered and sound enamel. IV. Trace element composition. Arch Oral Biol 1966;11:273-278.

Losee FL, Adkins BL: Anti-cariogenic effect of minerals in food and water. Nature 1968; 219:630-631. 
Losee FL, Adkins BL: A study of the mineral environment of caries-resistant Navy recruits. Caries Res 1969;3:23-31.

- Losee FL, Adkins BL, Curzon ME: Effect of water solids on dental caries in the rat. Caries Res 1976;10:332-336.

Losee FL, Bibby BG: Caries inhibition by trace elements other than fluorine. NY State Dent J 1970;36:15-19.

Losee FL, Curzon ME, Little MF: Trace element concentrations in human enamel. Arch Oral Biol 1974a;19:467-470.

Losee FL, Cutress TW, Brown R: Natural elements of the periodic table in human dental enamel. Caries Res 1974b;8:123-134.

-Losee FL, Ludwig TG: Trace elements and caries. J Dent Res 1970;49:1229-1236.

-Ludwig TG, Adkins BL, Losee FL: Relationship of concentrations of eleven elements in public water supplies to caries prevalence in American schoolchildren. Aust Dent J 1970; 15:126-132.

Lundberg M, Soeremark R, Thilander H: The concentration of some elements in the enamel of unerupted (impacted) human teeth. Odontol Revy 1965;16:8-11.

-Luoma H, Seppa L, Koskinen M, Syrjanen S: Effect of chlorhexidine-fluoride applications without and with Sr and Zn on caries, plaque, and gingiva in rats. J Dent Res 1984;63:11931196.

Marie PJ, Ammann P, Boivin G, Rey C: Mechanisms of action and therapeutic potential of strontium in bone. Calcif Tissue Int 2001;69: 121-129.

-Markovic M, Brecevic L: The role of strontium in the precipitation system $\mathrm{CaCl} 2-\mathrm{SrCl}_{2}-$ H3PO4-NaOH-H2O-0.15m NaCl. J Cryst Growth 1992;118:93-100.

-Matsunaga K, Murata H: Strontium substitution in bioactive calcium phosphates: a first-principles study. J Phys Chem B 2009;113:35843589.

Mellberg JR, Fletcher R: Effect of a strontium complex on fluoride uptake by artificial caries lesions and sound enamel in vitro. Caries Res 1990;24:93-96.

-Menczel J, Posner AS, Schraer H, Pakis G, Likins RC: Comparative fixation of Sr89 and Ca45 by calcified tissues as related to fluoride induced changes in crystallinity. Proc Soc Exp Biol Med 1962;110:609-613.

Meyerowitz C, Spector PC, Curzon ME: Pre- or post-eruptive effects of strontium alone or in combination with fluoride on dental caries in the rat. Caries Res 1979;13:203-210.

-Möller B, Carlsson LE: Particle-induced X-ray emission (PIXE) analysis of trace elements in human coronal dentin. Swed Dent J 1984;8: 67-72.

Navia JM: Prevention of dental caries: agents which increase tooth resistance to dental caries. Int Dent J 1972;22:427-440.

Neiman A, Eisenmann DR: The effect of strontium, cobalt and fluoride on rat incisor enamel formation. Anat Rec 1975; 183:303321.
Nelson DG, Featherstone JD, Duncan JF, Cutress TW: Paracrystalline disorder of biological and synthetic carbonate-substituted apatites. J Dent Res 1982;61:1274-1281.

Neuman WF, Bjornerstedt R, Mulryan BJ: Synthetic hydroxy apatite crystals. II. Aging and strontium incorporation. Arch Biochem Biophys 1963;101:215-224.

Nishino M: Effect of mouth rinses of a zinc acetate/strontium acetate/tannic acid mixture on caries activity in children. J Pedod 1981;5 136-141.

Nixon GS, Helsby CA: The relationship between strontium in water supplies and human tooth enamel. Arch Oral Biol 1976;21:691695.

Noren JG, Lodding A, Odelius H, Linde A: Secondary ion mass spectrometry of human deciduous enamel. Distribution of $\mathrm{Na}, \mathrm{K}, \mathrm{Mg}$, Sr, F and Cl. Caries Res 1983;17:496-502.

- Ogawa Y, Ishida T, Yagi T: Ultramicroscopy of hypomineralized responses in rat incisor dentine to injected strontium. Arch Oral Biol 1981;26:229-236.

-Okayama S, Akao M, Nakamura S, Shin Y, Higashikata M, Aoki H: The mechanical properties and solubility of strontium-substituted hydroxyapatite. Biomed Mater Eng 1991;1: 11-17.

Olson BL: Trace elements and dental caries. J Indiana Dent Assoc 1987;66:27-30.

Olson BL, McDonald JL Jr, Stookey GK: The effect of strontium and fluoride upon in vitro plaque and rat caries. J Dent Res 1978;57:903.

-Pan HB, Li ZY, Lam WM, Wong JC, Darvell BW, Luk KDK, Lu WW: Solubility of strontiumsubstituted apatite by solid titration. Acta Biomater 2009a;5:1678-1685.

$\rightarrow$ Pan HB, Li ZY, Wang T, Lam WM, Wong CT, Darvell BW, Luk KDK, Hu Y, Lu WW: Nucleation of strontium-substituted apatite. Cryst Growth Des 2009b;9:3342-3345.

- Parnell C, Whelton H, O'Mullane D: Water fluoridation. Eur Arch Paediatr Dent 2009;10: 141-148.

- Pearce EI, Sissons CH: The concomitant deposition of strontium and fluoride in dental plaque. J Dent Res 1987;66:1518-1522.

-Retief DH, Cleaton-Jones PE, Turkstra J, De Wet WJ: The quantitative analysis of sixteen elements in normal human enamel and dentine by neutron activation analysis and high-resolution gamma spectrometry. Arch Oral Biol 1971;16:1257-1267.

Riyat M, Sharma DC: Significance of trace element profile of blood of persons with multiple caries versus sound teeth. Biol Trace Elem Res 2010;134:174-179.

- Root MJ: Inhibition of the amorphous calcium phosphate phase transformation reaction by polyphosphates and metal ions. Calcif Tissue Int 1990;47:112-116.

Rytömaa I, Kolehmainen L, Tuompo H: Strontium content of deciduous teeth in northern and southern Finland. Acta Odontol Scand $1975 ; 33: 115-118$
Saleeb FZ, DeBruyn PL: Surface properties of alkaline earth apatites. J Electroanal Chem 1972;37:99-118.

-Schamschula RG, Adkins BL, Barmes DE, Charlton G, Davey BG: Caries experience and the mineral content of plaque in a primitive population in New Guinea. J Dent Res 1977; 56(Spec Iss):C62-C70.

Schamschula RG, Adkins BL, Barmes DE, Charlton G, Davey BG: WHO Study of Dental Caries Etiology in Papua New Guinea. Geneva, World Health Organization, 1978a.

-Schamschula RG, Bunzel M, Agus HM, Adkins BL, Barmes DE, Charlton G: Plaque minerals and caries experience: associations and interrelationships. J Dent Res 1978b;57:427432.

Schoenberg HP: Extent of strontium substitution for calcium in hydroxyapatite. Biochim Biophys Acta 1963;75:96-103.

Schroeder HA, Tipton IH, Nason AP: Trace metals in man: strontium and barium. J Chronic Dis 1972;25:491-517.

- Seppä L, Nykanen I, Spets-Happonen S, Luoma $\mathrm{H}$ : Prevention of fissure caries in rats by dietary $\mathrm{F}$ supplement with and without topical application of F and Sr + F. Caries Res 1988; 22:353-356.

- Shashikiran ND, Subba Reddy VV, Hiremath MC: Estimation of trace elements in sound and carious enamel of primary and permanent teeth by atomic absorption spectrophotometry: an in vitro study. Indian J Dent Res 2007; 18:157-162.

-Shaw JH, Griffiths D: Development and post-developmental influences on incidence of experimental dental caries resulting from dietary supplementation by various elements. Arch Oral Biol 1961;5:301-322.

- Shields CP, Curzon ME, Featherstone JD: Strontium concentrations in plaque fluids and solids. Caries Res 1984;18:495-498.

- Shigemi T, Tanaka T, Hayashida Y, Maki K Study of salivary strontium and silver concentrations in primary school children related to dental caries. Biol Trace Elem Res 2008;123:80-90.

-Söremark R, Samsahl K: Gamma-ray spectrometric analysis of elements in normal human enamel. Arch Oral Biol 1961;6:275-283.

-Söremark R, Samsahl K: Gamma-ray spectrometric analysis of elements in normal human dentin. J Dent Res 1962;41:603-606.

- Spector PC, Curzon ME: Relationship of strontium in drinking water and surface enamel. J Dent Res 1978;57:55-58.

- Spector PC, Curzon ME: Surface enamel fluoride and strontium in relation to caries prevalence in man. Caries Res 1979;13:227-230.

-Spector PC, Lang CC, Parmeter D: Strontium in surface enamel of rat molars. Caries Res 1978;12:264-267.

-Spets-Happonen S, Luoma H, Seppa L: High strontium addition to chlorhexidine-fluoride gel does not increase its caries-preventive effect in rats. Acta Odontol Scand 1996; 54:92-95. 
Spets-Happonen S, Seppa L, Korhonen A, Alakuijala P: Accumulation of strontium and fluoride in approximal dental plaque and changes in plaque microflora after rinsing with chlorhexidine-fluoride-strontium solution. Oral Dis 1998;4:114-119.

-Steadman LT, Brudevold F, Smith FA: Distribution of strontium in teeth from different geographic areas. J Am Dent Assoc 1958;57: 340-344.

-Stookey GK, Warrick JM, Miller LL, Greene AL: Animal caries models for evaluating fluoride dentifrices. Adv Dent Res 1995;9:198-207; discussion 208-213.

-Stranick MA, Root MJ: Influence of strontium on monofluorophosphate uptake by hydroxyapatite - XPS characterization of the hydroxyapatite surface. Coll Surf 1991;55: 137-147.

- Suga S, Aoki H, Yamashita Y, Tsuno M, Ogawa M: A comparative study of disturbed mineralization of rat incisor enamel induced by strontium and fluoride administration. Adv Dent Res 1987;1:339-355.

-Surdacka A, Stopa J, Torlinski L: In situ effect of strontium toothpaste on artificially decalcified human enamel. Biol Trace Elem Res 2007;116:147-153.

Tatevossian A, Wright WG: The collection and analysis of resting rat saliva. Arch Oral Biol $1974 ; 19: 825-827$.
Thuy TT, Nakagaki H, Kato K, Hung PA, Inukai J, Tsuboi S, Nakagaki H, Hirose MN, Igarashi S, Robinson C: Effect of strontium in combination with fluoride on enamel remineralization in vitro. Arch Oral Biol 2008;53: 1017-1022.

Verberckmoes SC, Behets GJ, Oste L, Bervoets AR, Lamberts LV, Drakopoulos M, Somogyi A, Cool P, Dorriné W, De Broe ME, D’Haese PC: Effects of strontium on the physicochemical characteristics of hydroxyapatite. Calcif Tissue Int 2004;75:405-415.

Vogel GL, Shim D, Schumacher GE, Carey CM, Chow LC, Takagi S: Salivary fluoride from fluoride dentifrices or rinses after use of a calcium pre-rinse or calcium dentifrice. Caries Res 2006;40:449-454.

Vrbic V, Stupar J: Dental caries and the concentration of aluminium and strontium in enamel. Caries Res 1980;14:141-147.

-Wefel JS, Jensen ME, Triolo PT, Faller RV, Hogan MM, Bowman WD: De/remineralization from sodium fluoride dentifrices. Am J Dent 1995;8:217-220.

Weinmann JP: The effect of strontium on the incisor of the rat: I. Injections of small doses of strontium chloride as a means of measuring the rate of incremental dentin apposition. J Dent Res 1942;21:497-504.

Weinmann JP: Recovery of ameloblasts. J Am Dent Assoc 1943;30:874-888.

White BA, Deaton TG, Bawden JW: In vivo and in vitro study of $90 \mathrm{Sr}$ in developing rat molar enamel. J Dent Res 1980;59:2091-2099.

-White DJ: The comparative sensitivity of intraoral, in vitro, and animal models in the profile evaluation of topical fluorides. J Dent Res 1992;71(Spec Iss):884-894.
White DJ, Nelson DG, Faller RV: Mode of action of fluoride: application of new techniques and test methods to the examination of the mechanism of action of topical fluoride. Adv Dent Res 1994;8:166-174.

-Yaeger JA: Finer structure of the matrix of the response in rat incisor dentin to injected strontium. J Dent Res 1963;42:1178-1182.

-Yaeger JA: Recovery of rat incisor dentin from abnormal mineralization produced by strontium and fluoride. Anat Rec 1966;154:661673.

Yaeger JA, Eisenmann DR: Response in rat incisor dentin to injected strontium, fluoride, and parathyroid extract. J Dent Res 1963;42: 1208-1216.

Yaeger JA, Hinrichsen CF, Cohen MJ: Development of the response in rat incisor dentin to injected strontium and fluoride. Am J Anat 1964;114:255-272.

Zaichick VY, Ovchjarenko NN: In vivo X-ray fluorescent analysis of $\mathrm{Ca}, \mathrm{Zn}, \mathrm{Sr}$, and $\mathrm{Pb}$ in frontal tooth enamel. J Trace Microprobe Techn 1996;14:143-152.

Zaichick VY, Ovchjarenko N, Zaichick S: In vivo energy dispersive X-ray fluorescence for measuring the content of essential and toxic trace elements in teeth. Appl Radiat Isot 1999;50:283-293.

Zero DT, Curzon ME, Zander HA: Physical and chemical effects of toothpastes on dental enamel. J Dent Res 1982;61:451-455. 